\title{
Formulation Development and Evaluation of Sustain Release Gastroretentive Floating Tablets of Prochlorperazine Dimaleate
}

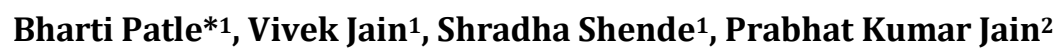 \\ ${ }^{1}$ NRI Institute of Pharmacy, Bhopal, Madhya Pradesh, India \\ ${ }^{2}$ Scan Research Laboratories, Bhopal, Madhya Pradesh, India
}

\begin{abstract}
Floating drug delivery systems are the gastroretentive forms that precisely control the release rate of target drug to a specific site which facilitate an enormous impact on health care. The purpose of this research was to develop a novel gastro retentive drug delivery system based on direct compression method for sustained delivery of active agent to improve the bioavailability, reduce the number of doses and to increase patient compliance. Gastro retentive floating tablets of Prochlorperazine dimaleate (PCZ) were prepared by direct compression method using altered concentrations of HPMC K4, HPMC K15 and PVP K30 as polymers. The prepared tablets of PCZ were evaluated for hardness, thickness, friability, weight variation, drug content uniformity, buoyancy lag time, total floating time, in-vitro dissolution study, etc. All the compositions were resulted in adequate Pharmacopoeial limits. Compatibility studies was execution during FTIR shown that there was absence of probable chemical interaction between pure drug and excipients. The varying concentration of gas generating agent and polymers was fou nd to affect on in-vitro drug release and floating lag time. In vitro drug release of floating gastro retentive tablet of PCZ shown that the formulation F9 was found to be the best formulation as it releases $98.89 \%$ in a controlled manner for an extended period of time (up to 12 hrs). The release data was fitted to various mathematical models such as Higuchi, Korsmeyer-Peppas, First order and Zero order to evaluate the kinetics and mechanism of the drug release. The optimized formulation (F9) showed no significant change in physical appearance, drug content, floating lag time, in vitro dissolution studies after $75 \% \pm 5 \%$ RH at $40 \pm 20 \mathrm{C}$ relative humidity for 6 months. Prepared floating tablets of PCZ may prove to be a potential candidate for safe and effective controlled drug delivery over an extended period of time for gastro retentive dr ug delivery system.
\end{abstract}

Keywords: Prochlorperazine dimaleate, Floating tablet, Gastro retentive, Total floating time.

Article Info: Received 12 June 2019; $\quad$ Review Completed 19 July 2019; $\quad$ Accepted 07 Aug 2019; Available online 15 August 2019

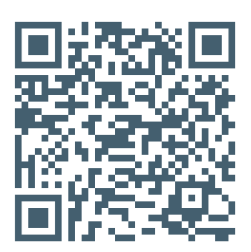

Cite this article as:

Patle B, Jain V, Shende S, Jain PK, Formulation Development and Evaluation of Sustain Release Gastroretentive Floating Tablets of Prochlorperazine Dimaleate, Journal of Drug Delivery and Therapeutics. 2019; 9(4-s):445-450

http://dx.doi.org/10.22270/jddt.v9i4-s.3353

Bharti Patle, NRI Institute of Pharmacy, Bhopal, Madhya Pradesh, India

\section{INTRODUCTION}

The oral route is considered as the most promising route of drug delivery. Drugs with narrow absorption window in the GIT have poor absorption ${ }^{1}$. Therefore, Grdds have been developed, which prolong gastric emptying time of drug and offers numerous advantages; improves bioavailability, reduces drug waste and improves solubility for drugs that are less soluble in a high pH environment of small intestine 2 . To formulate a successful stomach specific or gastroretentive drug delivery system, several techniques are currently used such as HBS or floating drug delivery systems, low density systems, raftsystems, incorporating alginate gels, bioadhesive or mucoadhesive systems, super porous hydrogels and magnetic systems. Swellable, floating and SR tablets are developed by using a combination of hydrophilic polymers (HPMC), swelling agents (crosspovidone and crosscarmellose sodium) and effervescent substances $\left(\mathrm{NaHCO}_{3}\right.$ and citric acid). Prochlorperazine dimaleate (also known as Prochlorperazin, Compazine, Capazine, Stemetil), the dimaleate salt of Prochlorperazine, is a dopamine (D2) receptor antagonist that belongs to the phenothiazine class of antipsychotic agents that are used for the antiemetic treatment of nausea and vertigo. It is also a highly potent typical antipsychotic, 10-20 times more potent than chlorpromazine. Prochlorperazine dimaleate is also used to treat migraine headaches. The objective of the present research work was to provide gastroretentive formulation that will provide once daily, sustained release dosage form of $\mathrm{PCZ}^{3}$.

\section{MATERIALS AND METHODS}

\section{Materials}

Prochlorperazine dimaleate was purchased from Sigma Aldrich-Merck, Bengaluru, Karnataka, India. Hydroxypropyl methylcellulose (HPMC K4M, HPMC K15M) was procured from Meditab Specialities Pvt. Ltd., Satara. PVP K30 was purchased from S.D fine chemicals, Mumbai. Sodium 
bicarbonate, Citric acid, magnesium stearate, talc were purchased from Mapromax, Life sciences Pvt. Ltd., Dehradun. Other solvents and chemicals used in the research were of LR grade. All the studies were carried in distilled water.

\section{Methods}

\section{Preformulation studies}

\section{Standardization of PCZ by UV-Visible spectrophotometry}

Accurately weighed $10 \mathrm{mg}$ of drug was dissolved in $10 \mathrm{ml}$ of $0.1 \mathrm{~N} \mathrm{HCl}$ solutions in $10 \mathrm{ml}$ of volumetric flask. The resulted solution $1000 \mu \mathrm{g} / \mathrm{ml}$ and from this solution $1 \mathrm{ml}$ pipette out and transfer into $10 \mathrm{ml}$ volumetric flask and volume make up with $0.1 \mathrm{~N} \mathrm{HCl}$ solution and prepare suitable dilution to make it to a concentration range of $2-10 \mu \mathrm{g} / \mathrm{ml}$. The spectrum of this solution was run in $200-400 \mathrm{~nm}$ range in U.V. spectrophotometer (Labindia-3000+).

\section{Fourier transform infrared (FTIR) spectroscopy}

The physical properties of the physical assortment were comparing with those of lafutidine pure drug. Samples was assorted comprehensively through $100 \mathrm{mg}$ potassium bromide IR powder as well as compacted under vacuum at a pressure of concerning 12 psi for 3 minutes. The ensuing disc was mounted in an appropriate holder in Brukers Alpha IR spectrophotometer and the IR spectrum was recorded from $3500 \mathrm{~cm}$ to $500 \mathrm{~cm}$. The resultant spectrum was compared for any spectrum changes.

\section{Pre compression evaluation}

Flow properties and compressibility properties of powder mixture were evaluated by measurement of angle of repose, bulk density, tapped density, carr's index, and hausner ratio.

\section{Angle of repose $(\theta)$}

The angle of repose was determined by using fixed funnel method. The physical mixtures of drug with different excipients were prepared and the accurately weighed drug powder or its physical mixture was taken in a funnel. The height of the funnel was adjusted in such a way that the tip of the funnel just touches the apex of the heap of the drug powder. The powder was allowed to flow through the funnel freely onto surface. The angle of repose was calculated using the following equation.

$$
\theta=\tan -1(\mathrm{~h} / \mathrm{r})
$$

Where, $\mathrm{h}$ and $\mathrm{r}$ are the height and radius of the powder cone respectively.

\section{Bulk density}

Both loose bulk density (LBD) and tapped density (TBD) were determined were calculated using the following formulas.

LBD $=$ Powder weight/volume of the packing

TBD = Powder weight /tapped volume of the packing

\section{Compressibility index}

The compressibility index of the granules was determined by Carr's compressibility index.

$$
\text { Carr's index }(\%)=[(\mathrm{TBD}-\mathrm{LBD}) / \mathrm{TBD}] \times 100 \text {. }
$$

\section{Hausner's ratio}

Hausner's ratio is an indirect index of ease of measuring the powder flow. It was calculated by the following formula ${ }^{4-6}$

Hausner's ratio $=$ Tapped density/Bulk density.

\section{Formulation development of tablets}

\section{Direct compression method}

Different tablets formulations (F1-F9) were prepared by direct compression technique. All powders were passed through 40 meshes. Required quantities of drug and polymers were mixed thoroughly Magnesium stearate was added as lubricant. Talc was used as glidant. Lactose was used as diluents. Finally the powder mix was subjected to compression after mixing uniformly in a polybag. Prior to compression, the blends were evaluated for several tests ${ }^{7}$. The composition of PCZ floating tablets was shown in Table

\begin{tabular}{|c|c|c|c|c|c|c|c|c|c|}
\hline Excipients(mg) & F1 & F2 & F3 & F4 & F5 & F6 & F7 & F8 & F9 \\
\hline $\begin{array}{l}\text { Prochlorperazine } \\
\text { Dimaleate }\end{array}$ & 5 & 5 & 5 & 5 & 5 & 5 & 5 & 5 & 5 \\
\hline HPMC K 15 & 80 & 100 & 120 & - & - & - & 40 & 50 & 60 \\
\hline HPMC K 4 & - & - & - & 80 & 100 & 120 & 40 & 50 & 60 \\
\hline PVP K30 & 15 & 15 & 15 & 15 & 15 & 15 & 15 & 15 & 15 \\
\hline Citric acid & 5 & 5 & 5 & 5 & 5 & 5 & 5 & 5 & 5 \\
\hline $\mathrm{NaHCO}_{3}$ & 20 & 20 & 20 & 20 & 20 & 20 & 20 & 20 & 20 \\
\hline $\operatorname{Mg}\left(\mathrm{C}_{18} \mathrm{H}_{35} \mathrm{O}_{2}\right)_{2}$ & 5 & 5 & 5 & 5 & 5 & 5 & 5 & 5 & 5 \\
\hline Talc & 5 & 5 & 5 & 5 & 5 & 5 & 5 & 5 & 5 \\
\hline Lactose & 65 & 45 & 25 & 65 & 45 & 25 & 65 & 45 & 25 \\
\hline Total Weight & 200 & 200 & 200 & 200 & 200 & 200 & 200 & 200 & 200 \\
\hline
\end{tabular}

Table 1 Formulation composition of PCZ gastro retentive tablets

\section{Evaluation of tablets}

All the tablets were evaluated for following different parameters which includes;

\section{General appearance}

Five tablets from different batches were randomly selected and organoleptic properties such as color, odor, taste, shape were evaluated. Appearance was judged visually.

\section{Thickness and diameter}

Thickness and diameter of tablets were determined using Vernier caliper. Five tablets from each batch were used, and an average value was calculated.

\section{Hardness}

For each formulation, the hardness of five tablets was determined using the Monsanto hardness tester (Cadmach). 


\section{Friability}

The friability of a sample of 10 tablets was measured using a Friability tester (Electro Lab).Ten tablets were weighed, rotated at $25 \mathrm{rpm}$ for 4 minutes. Tablets were reweighed after removal of fines (dedusted) and the percentage of weight loss was calculated.

\section{Uniformity of weight}

Twenty tablets were randomly selected from each batch individually weighed, the average weight and standard deviation of 20 tablets was calculated.

\section{Drug content}

Twenty tablets were taken and amount of drug present in each tablet was determined. The tablets were crushed in a mortar and the powder equivalent to $100 \mathrm{mg}$ of drug was transferred to $100 \mathrm{ml}$ standard flask. The powder was dissolved in $50 \mathrm{ml}$ of $0.1 \mathrm{~N} \mathrm{HCl}$ and made up to volume with of $0.1 \mathrm{~N} \mathrm{HCl}$. The sample was mixed thoroughly and filtered through a $0.45 \mu$ membrane filter. The filtered solution was diluted suitably and analyzed for drug content by UV spectrophotometer at a $\lambda$ max of $256 \mathrm{~nm}$ using of $0.1 \mathrm{~N} \mathrm{HCl}$ as blank.

\section{In vitro buoyancy studies}

In vitro buoyancy was determined by floating lag time as per the method described by Rosa et $a l^{8}$. The tablets were separately in a $100 \mathrm{ml}$ glass beaker containing simulated gastric fluid (SGF), pH 1.2 as per USP. The time necessary for the tablet to increase to the outside and float was determined as floating lag time. The experiments were conducted in triplicate. Total floating times were measured during in vitro dissolution studies.

\section{Dissolution rate studies}

In vitro drug release of the sample was done using USP-type II dissolution apparatus (Paddle type). The dissolution medium, $900 \mathrm{ml} 0.1 \mathrm{~N} \mathrm{HCl}$ was set into the dissolution flask maintaining the temperature of $37 \pm 0.5^{\circ} \mathrm{C}$ and rpm of 75 . One PCZ tablet was set in every container of dissolution apparatus. The mechanical assembly was permitted to keep running for 10 hours. Sample measuring $5 \mathrm{ml}$ were pulled back after each 1 hour up to 10 hours using $10 \mathrm{ml}$ pipette. The new disintegration medium $\left(37^{\circ} \mathrm{C}\right)$ was supplanted each time with a similar amount of the sample and takes the absorbance at $256 \mathrm{~nm}$ using spectroscopy ${ }^{9-11}$.

Mathematical treatment of in-vitro release data: The quantitative analysis of the qualities got in dissolution/release tests is simpler when mathematical formulas that express the dissolution comes about as an element of a portion of the measurement frames attributes are utilized.

Zero-order kinetics: The pharmaceutical dosage frames following this profile release a similar measure of medication by unit of time and it is the ideal method of medication release keeping in mind the end goal to accomplish a pharmacological prolonged action. The following relation can, in a simple way, express this model:

$$
Q_{t}=Q_{o}+K_{o} t
$$

where $Q_{t}$ is the amount of drug dissolved in time $t, Q_{o}$ is the initial amount of drug in the solution (most times, $Q_{0}=0$ ) and $\mathrm{K}_{\mathrm{o}}$ is the zero order release constant.

First-order kinetics: The following relation expresses this model:

$$
\log Q_{t}=\log Q_{0}+\frac{K_{1} t}{2.303}
$$

where $Q_{t}$ is the amount of drug dissolved in time $t, Q_{o}$ is the initial amount of drug in the solution and $\mathrm{K}_{1}$ is the zero order release constant.

Along these lines a graphic of the decimal logarithm of the released measure of drug versus time will be linear. The pharmaceutical dosage shapes following this dissolution profile, for example, those containing water-solvent drugs in permeable frameworks, discharge drug in a way that is corresponding to the measure of drug staying in its inside, in such way, that the measure of drug released by unit of time reduce.

Higuchi model: Higuchi built up a few theoretical models to ponder the arrival of water-solvent and low dissolvable medications in semi-strong or potentially strong grids. Mathematical expressions were acquired for sedate particles scattered in a uniform grid acting as the diffusion media. The simplified Higuchi model is expressed as:

$$
\mathrm{Q}=\mathrm{K}_{\mathbf{H}} \cdot \mathbf{t}^{\mathbf{1} / 2}
$$

Where $Q$ is the amount of drug released in time $t$ and $K_{H}$ is the Higuchi dissolution constant. Higuchi model describes drug release as a diffusion process based in the Fick's law, square root time dependent. This relation can be utilized to portray the drug dissolution from a few kinds of modified release pharmaceutical dosage structures, for example, transdermal systems and matrix tablets with waterdissolvable drugs.

Korsmeyer-Peppas model: Korsmeyer et al. used a simple empirical equation to describe general solute release behaviour from controlled release polymer matrices:

$$
\frac{M_{\mathbf{t}}}{\mathbf{M}_{\mathbf{w}}}=\mathbf{a} \mathbf{t}^{n}
$$

where $M_{t} / M_{\infty}$ is fraction of drug released, a is kinetic constant, $\mathrm{t}$ is release time and $\mathrm{n}$ is the diffusional exponent for drug release. ' $n$ ' is the slope value of $\log M_{t} / M_{\infty}$ versus log time curve. Peppas stated that the above equation could adequately describe the release of solutes from slabs, spheres, cylinders and discs, regardless of the release mechanism. Peppas used this $\mathrm{n}$ value in order to characterize different release mechanisms, concluding for values for a slab, of $n=0.5$ for fickian diffusion and higher values of $n$ between 0.5 and 1.0, or $n=1.0$, for mass transfer following a non-fickian model. In case of a cylinder $n=0.45$ instead of 0.5 , and 0.89 instead of 1.0. This equation can only be used in systems with a drug diffusion coefficient fairly concentration independent. To the determination of the exponent $n$ the portion of the release curve where $\mathrm{M}_{\mathrm{t}} / \mathrm{M}_{\infty}<0.6$ should only be used. To use this equation it is also necessary that release occurs in a one-dimensional way and that the system widththickness or length-thickness relation be at least 10. A modified form of this equation was developed to accommodate the lag time $(I)$ in the beginning of the drug release from the pharmaceutical dosage form:

$$
\frac{\mathrm{M}_{\mathbf{t}-l}}{\mathbf{M}_{\mathbf{s}}}=\mathbf{a}(\mathbf{t}-l)^{n}
$$

When there is the possibility of a burst effect, $b$, this equation becomes:

$$
\frac{\mathbf{M}_{\mathbf{t}}}{\mathbf{M}_{\mathbf{o}}}=\mathbf{a} \mathbf{t}^{2}+\mathbf{b}
$$


In the absence of lag time or burst effect, $l$ and $b$ value would be zero and only at ${ }^{n}$ is used. This mathematical model, also known as Power Law, has been used very frequently to describe release from several different pharmaceutical modified release dosage forms ${ }^{12-14}$.

\section{Stability studies}

The optimized formulation of PCZ were packed in strips of $0.04 \mathrm{~mm}$ thick aluminum foil laminated with poly vinyl chloride by strip packing and these packed formulations were stored in ICH certified stability chambers (Thermo labs, Mumbai) maintained at 40 0C and 75\% RH for 6 months. The samples were withdrawn periodically and evaluated for their floating lag time, content uniformity and for in vitro drug release.

\section{RESULTS AND DISCUSSION}

The $\lambda$ max of PCZ was found to be $256 \mathrm{~nm}$ by using U.V. spectrophotometer (Labindia-3000+) in linearity range 2$10 \mu \mathrm{g} / \mathrm{ml}$ Figure1, 2. Identification of betahistine was done by FTIR spectroscopy with respect to marker compound. It was identified from the result of IR spectrum as per specification. Tablet powder blend was subjected to various preformulation parameters Table 2. The angle of repose values indicates that the powder blend has good flow properties. The bulk density and tapped density of all the formulations was found to be in the range of 0.349 to $0.365(\mathrm{gm} / \mathrm{ml})$ and 0.438 to0.485 showing that the powder has good flow properties. The compressibility index of all the formulations was found to be ranging between 20.320 to 26.186 which shows that the powder has good flow properties. All the formulations have shown the Hauser's ratio ranging between 1.255to 1.355indicating the powder has good flow properties. PCZ tablet quality control tests such as weight variation, hardness and friability, thickness, drug content and drug release studies in different media were performed on the compression tablet. All the parameters such as weight variation, hardness, friability, thickness and drug content were found to be within limits Table 3.

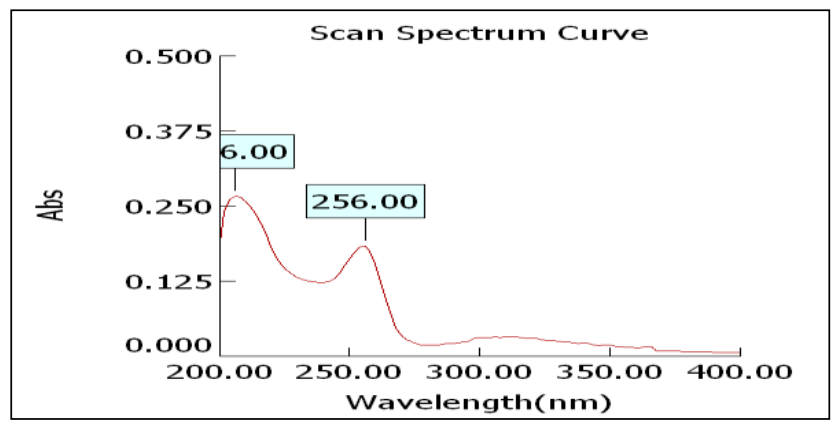

Figure 1 Determination of $\lambda_{\max }$ of prochlorparazine dimeliate

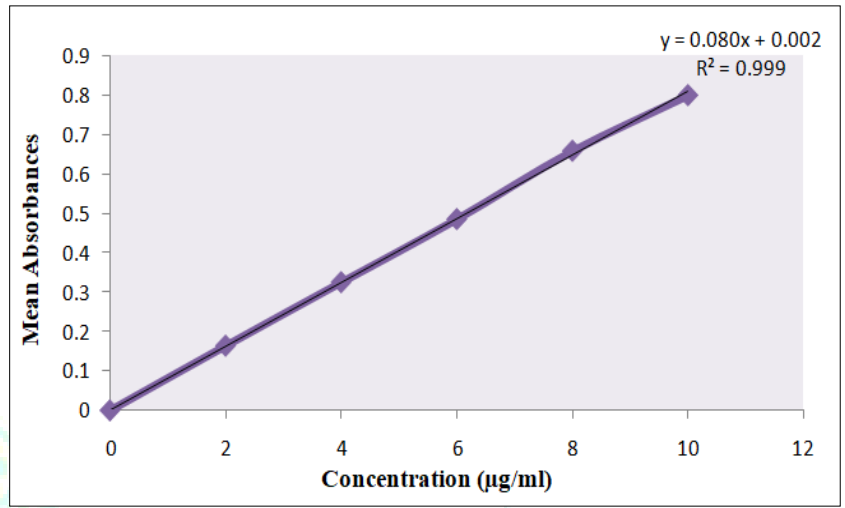

Figure 2 Calibration curve of prochlorperazine dimaleate at $256 \mathrm{~nm}$

Table 2 Result of pre-compression properties of PCZ FGR tablets

\begin{tabular}{|c|c|c|c|c|}
\hline $\begin{array}{c}\text { Formulation } \\
\text { code }\end{array}$ & $\begin{array}{c}\text { Bulk } \\
\text { density(gm/ml) }\end{array}$ & $\begin{array}{c}\text { Tapped } \\
\text { density(gm/ml) }\end{array}$ & $\begin{array}{c}\text { Compressibility } \\
\text { index }\end{array}$ & Hausner ratio \\
\hline F1 & 0.356 & 0.462 & 22.944 & 1.298 \\
\hline F2 & 0.359 & 0.458 & 21.616 & 1.276 \\
\hline F3 & 0.365 & 0.469 & 22.175 & 1.285 \\
\hline F4 & 0.362 & 0.472 & 23.305 & 1.304 \\
\hline F5 & 0.358 & 0.485 & 26.186 & 1.355 \\
\hline F6 & 0.359 & 0.478 & 24.895 & 1.331 \\
\hline F7 & 0.354 & 0.469 & 24.520 & 1.325 \\
\hline F8 & 0.358 & 0.458 & 21.834 & 1.279 \\
\hline F9 & 0.349 & 0.438 & 20.320 & 1.255 \\
\hline
\end{tabular}

Table 3 Results of post compression properties of PCZ FGR tablets

\begin{tabular}{|c|c|c|c|c|c|c|}
\hline F. Code & $\begin{array}{c}\text { Thickness } \\
\text { (mm) }\end{array}$ & $\begin{array}{c}\text { Diameter } \\
\text { (mm) }\end{array}$ & $\begin{array}{c}\text { Hardness (kg/cm2) } \\
\mathbf{N = 3}\end{array}$ & $\begin{array}{c}\text { Weight } \\
\text { variation (mg) }\end{array}$ & $\begin{array}{c}\text { Friability } \\
\text { (\%) }\end{array}$ & $\begin{array}{c}\text { Drug content } \\
\text { (\%) }\end{array}$ \\
\hline F1 & 3.46 & 9.8 & 4.8 & 205 & 0.589 & 98.85 \\
\hline F2 & 3.50 & 9.6 & 4.6 & 198 & 0.685 & 96.65 \\
\hline F3 & 3.47 & 9.8 & 4.7 & 200 & 0.458 & 99.56 \\
\hline F4 & 3.48 & 9.7 & 4.8 & 203 & 0.658 & 98.25 \\
\hline F5 & 3.49 & 9.8 & 4.6 & 205 & 0.521 & 97.85 \\
\hline F6 & 3.45 & 9.6 & 4.5 & 195 & 0.658 & 98.98 \\
\hline F7 & 3.44 & 9.5 & 4.8 & 203 & 0.965 & 99.12 \\
\hline F8 & 3.43 & 9.7 & 4.7 & 205 & 0.658 & 99.45 \\
\hline F9 & 3.46 & 9.8 & 4.8 & 201 & 0.785 & 99.36 \\
\hline
\end{tabular}

In the present study 9 formulations with variable concentration of polymers (HPMC K4, K 15) were prepared by direct compression method and evaluated for physicochemical properties. The results of buoyancy lag time, total floating time and in vitro drug release was given in Table 4, 5 \& Fig.3. The results indicated that optimizes 
formulation $\mathrm{F} 9$ on immersion in $0.1 \mathrm{~N} \mathrm{HCl}$ at $37 \pm 0.5^{\circ} \mathrm{C}$ tablets immediately and remain buoyant up to $12 \mathrm{hr}$ without disintegration. These 2 factors are essential for tablets to acquire density $<1$, so that it remains buoyant on the gastric fluids. The in vitro drug release data of the optimized formulation was subjected to goodness of fit test by linear regression analysis according to zero order, first order kinetic equation, higuchi's and korsmeyer's models in order to determine the mechanism of drug release. When the regression coefficient values of were compared, it was observed that ' $r$ ' values of Korsmeyer Peppas was maximum i.e. 0.977 hence indicating drug release from formulations was found to follow Korsmeyer Peppas model. Table 6, 7 \& Fig. 4-7.
Table 4 Results of in-vitro buoyancy study of PCZ FGR

\begin{tabular}{|c|c|c|}
\hline $\begin{array}{c}\text { Formulation } \\
\text { Code }\end{array}$ & $\begin{array}{c}\text { Floating lag times } \\
\text { (sec) }\end{array}$ & $\begin{array}{c}\text { Total floating } \\
\text { duration (h) }\end{array}$ \\
\hline F1 & 65 & $12 \mathrm{Hrs}$. \\
\hline F2 & 69 & $12 \mathrm{Hrs}$. \\
\hline F3 & 85 & $12 \mathrm{Hrs}$. \\
\hline F4 & 69 & $12 \mathrm{Hrs}$. \\
\hline F5 & 45 & $12 \mathrm{Hrs}$. \\
\hline F6 & 52 & $12 \mathrm{Hrs}$. \\
\hline F7 & 39 & $12 \mathrm{Hrs}$. \\
\hline F8 & 49 & $12 \mathrm{Hrs}$. \\
\hline F9 & 55 & $12 \mathrm{Hrs}$. \\
\hline
\end{tabular}

Table 5 In-vitro drug release study of GRF tablets

\begin{tabular}{|c|c|c|c|c|c|c|c|c|c|}
\hline Time & \multicolumn{9}{|c|}{ \% Cumulative Drug Release } \\
\hline (hr) & F1 & F2 & F3 & F4 & F5 & F6 & F7 & F8 & F9 \\
\hline 0.5 & 48.56 & 45.58 & 40.25 & 38.89 & 36.25 & 33.25 & 28.45 & 26.65 & 23.36 \\
\hline 1 & 78.89 & 75.56 & 68.98 & 49.98 & 42.25 & 40.56 & 36.45 & 30.35 & 26.69 \\
\hline 1.5 & 89.98 & 82.23 & 79.78 & 65.58 & 58.98 & 50.56 & 45.58 & 40.56 & 38.78 \\
\hline 2 & 96.56 & 95.56 & 88.78 & 78.89 & 75.58 & 70.25 & 65.56 & 61.25 & 45.25 \\
\hline 3 & & 98.98 & 95.56 & 90.12 & 88.98 & 81.25 & 73.32 & 70.25 & 55.56 \\
\hline 4 & & & 98.89 & 95.56 & 95.56 & 90.25 & 88.98 & 83.25 & 68.89 \\
\hline 6 & & & & 98.89 & 99.89 & 98.65 & 98.45 & 93.56 & 78.58 \\
\hline 8 & & & & & & & & 98.78 & 89.98 \\
\hline 12 & & & & & & & & & 98.89 \\
\hline
\end{tabular}

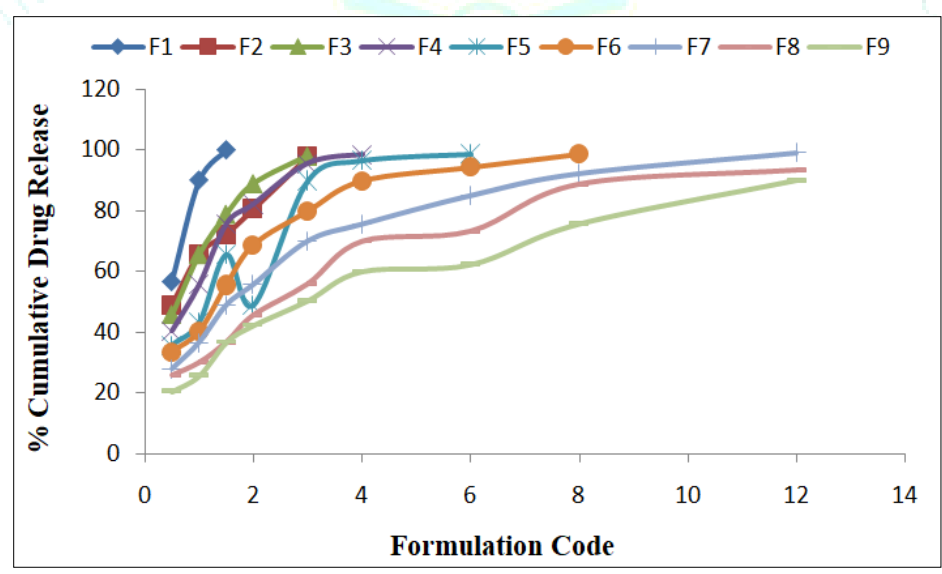

Figure 3 In-vitro drug release study of GRF tablets

Table 6 In-vitro drug release data for optimized formulation F9

\begin{tabular}{|c|c|c|c|c|c|c|}
\hline $\begin{array}{c}\text { Time } \\
\text { (h) }\end{array}$ & $\begin{array}{c}\text { Square Root } \\
\text { of Time(h) } \mathbf{1 / 2}\end{array}$ & Log Time & $\begin{array}{c}\text { Cumulative*\% Drug } \\
\text { Release }\end{array}$ & $\begin{array}{c}\text { Log Cumulative } \\
\text { \% Drug Release }\end{array}$ & $\begin{array}{c}\text { Cumulative \% } \\
\text { Drug Remaining }\end{array}$ & $\begin{array}{c}\text { Log Cumulative \% } \\
\text { Drug Remaining }\end{array}$ \\
\hline 0.5 & 0.707 & -0.301 & 23.36 & 1.368 & 76.64 & 1.884 \\
\hline 1 & 1 & 0 & 26.69 & 1.426 & 73.31 & 1.865 \\
\hline 1.5 & 1.225 & 0.176 & 38.78 & 1.589 & 61.22 & 1.787 \\
\hline 2 & 1.414 & 0.301 & 45.25 & 1.656 & 54.75 & 1.738 \\
\hline 3 & 1.732 & 0.477 & 55.56 & 1.745 & 44.44 & 1.648 \\
\hline 4 & 2 & 0.602 & 68.89 & 1.838 & 31.11 & 1.493 \\
\hline 6 & 2.449 & 0.778 & 78.58 & 1.895 & 21.42 & 1.331 \\
\hline 8 & 2.828 & 0.903 & 89.98 & 1.954 & 10.02 & 1.001 \\
\hline 12 & 3.464 & 1.079 & 98.89 & 1.995 & & 1.11 \\
\hline
\end{tabular}




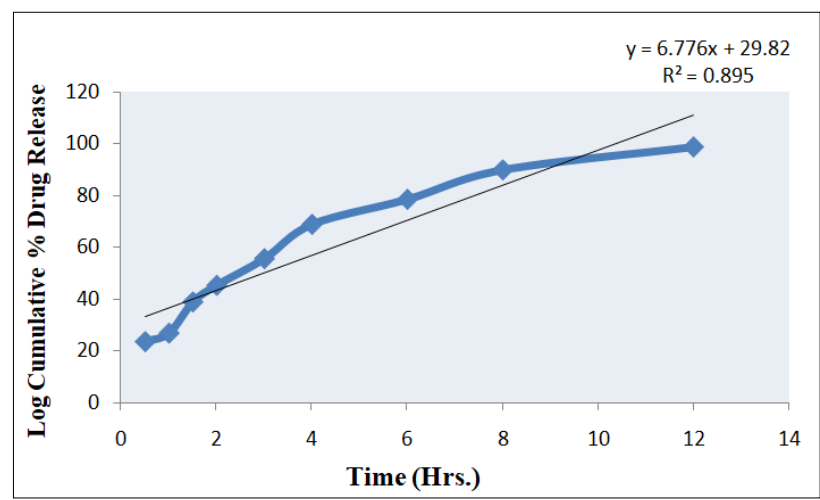

Figure 4 Zero order release Kinetics

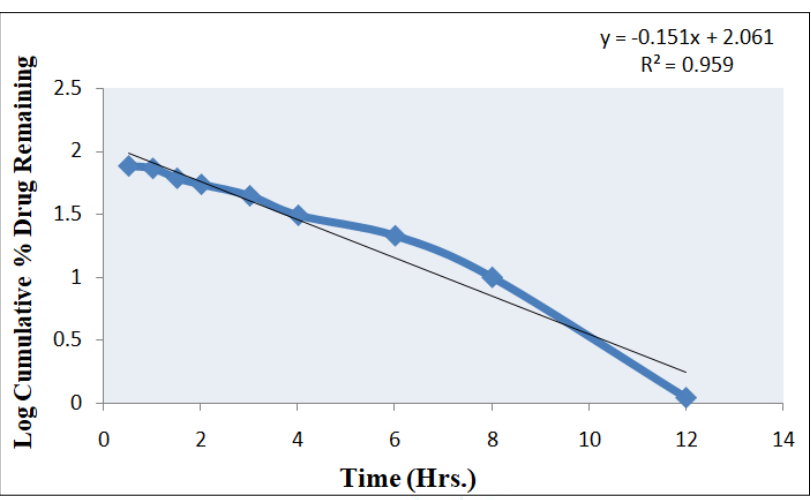

Figure 5 Fig. 5 First order release kinetics

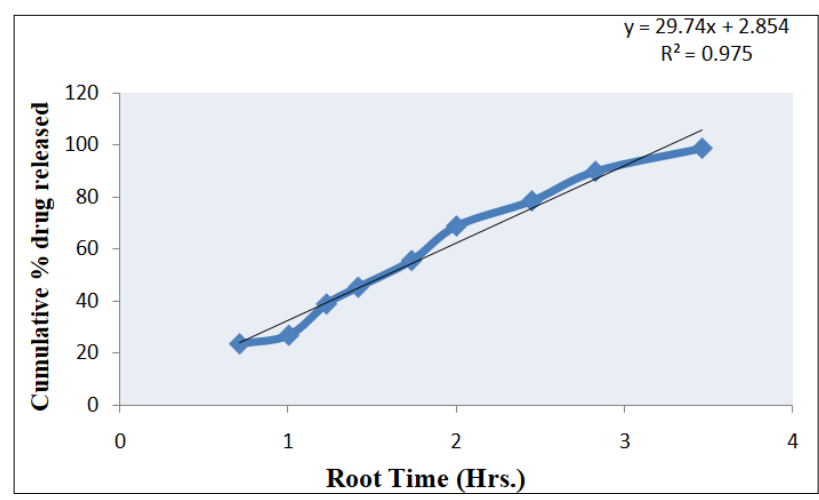

Figure 6 Higuchi release Kinetics

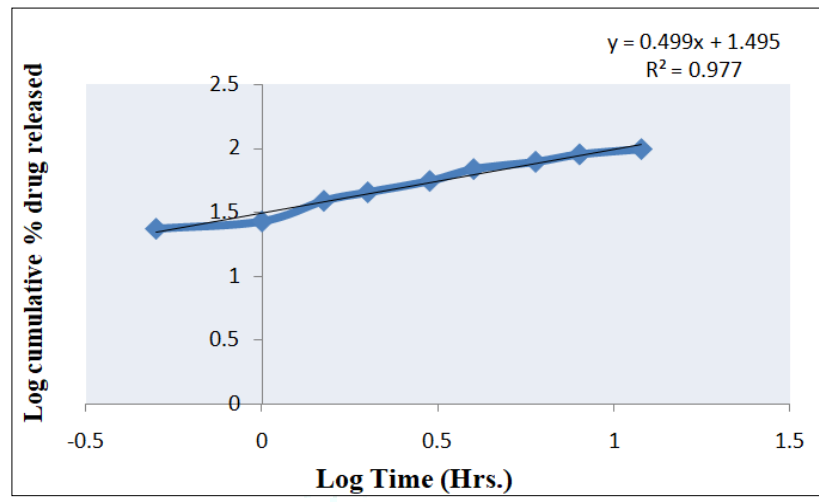

Figure 7 Korsmeyer-Peppas release Kinetics

Table 7 Regression analysis data of Prochlorperazine dimaleate Floating Tablets

\begin{tabular}{|c|c|c|c|c|}
\hline \multirow{2}{*}{ Batch } & Zero Order & First Order & Higuchi & Korsmeyer Peppas \\
\cline { 2 - 5 } & $\mathbf{R}^{\mathbf{2}}$ & $\mathbf{R}^{\mathbf{2}}$ & $\mathbf{R}^{\mathbf{2}}$ & $\mathbf{R}^{\mathbf{2}}$ \\
\hline F9 & 0.895 & 0.959 & 0.975 & 0.977 \\
\hline
\end{tabular}

\section{ACKNOWLEDGMENTS}

The authors would like to thank the Mr. Prabhat Kumar Jain, Geeta Parkhe and All supporting staff of Scan Research Laboratories, Bhopal (M.P.) who helped in the experiments during research work.

\section{CONCLUSION}

PCZ floating tablets were successfully formulated by floating technique. The optimized formulation (F9) was selected on the basis of in vitro buoyancy and in vitro drug release. The addition of gel forming agent and gas generating agent was essential to achieve in vitro buoyancy. The results of the in vitro drug release and in vitro buoyancy study showed that the optimized formulation (F9) sustained the drug release $(98.89 \%)$ up to $12 \mathrm{hrs}$ and remained buoyant for $>12 \mathrm{hrs}$. Optimized formulation (F9) does not show any significant change in physical appearance, floating properties and drug release after storage at $40^{\circ} \mathrm{C} / 75 \% \mathrm{RH}$ and stable for 3 months.

\section{REFERENCES}

1. Praveen N, Mahant S, Sharma D, Review: floating systems: A novel approach towards gastro retentive drug delivery systems. Int J Pharm 2010; 2.

2. Gendle R, Kaushik B, Verma S, Patel R, Singh SK, Namdeo KP. Formulation and evaluation of sustained release matrix tablet of Tramadol Hcl. Int J Chem Tech Res 2010; 2: 4-10.
3. Sweetman SC, editors. Martindale: The Complete Drug Reference. 33 ${ }^{\text {rd }}$ ed. London: Pharmaceutical Press, 2002. p.701.

4. Sinko PJ. Physical Pharmacy and Pharmaceutical Sciences, Lippincott Williams and Wilkins, 5th Edition, 2006.

5. Chein Y W. Novel drug delivery systems, Marcel Dekker, INC, 2nd edition, 1992, 140.

6. Liberman HA, Lachman L, Schwartz JB. Pharmaceutical dosage forms: Tablets, 3rd edition, Marcel Dekker, New York, 1990.

7. Ambati BR, Samyuktha Rani B, Eswar Tony D, Sivanaga Raja D. Aceclofenac floating tablets- a promising suatained release dosage form. Int J Drug Devel Res 2011; 3: 290-300.

8. Rosa M, Zia H, Rhodes T. Dosing and testing in-vitro of a bioadhesive and floating drug delivery system for oral application. Int J Pharm 1994; 105:65-70.

9. Rajesh K, Usharani E, Nagaraju R. Design and evaluation of sustained release floating tablets for the treatment of gastric ulcer. J Pharm Sci Res 2009; 1(4): 81-87.

10. Patil J M, Hirlekar R S, Gide P S. Trends in floating drug delivery systems, J Sci Indust Res 2006;65(01): 2006, 11-21.

11. Ritger P L, Peppas N A. A simple equation for description of solute release fickian and anomalous release from swellable devices, J Control Release 1987; 5(1): 37-42.

12. Brahamankar DM, Jaiswal SB. Biopharmaceutics and pharmacokinetics e a treatise, pharmacokinetics: basic consideration. 2nd ed. Vallabh Prakashan; 2009. pp. 240e3.

13. Higuchi T. Mechanism of sustained action medication, theoretical analysis of rate of release of solid drugs dispersed in solid matrices. J Pharm Sci 1963; 52:1145-9.

14. Korsmeyer RW, Gumy R, Doelker E, Buri P, Peppas NA. Mechanism of solute release from porous hydrophilic polymer. Int J Pharm 1983;15:25-35. 